\title{
Leptin receptor mediates the proliferation and glucose metabolism of pancreatic cancer cells via AKT pathway activation
}

\author{
YINGJIE XU $^{1 *}$, MEIYU TAN ${ }^{2 *}$, XIAOYU TIAN ${ }^{2}$, JUN ZHANG $^{3}$, JIE ZHANG $^{2}$, \\ JIAJIE CHEN ${ }^{2}$, WEIHONG XU ${ }^{2}$ and HUIMING SHENG ${ }^{2}$
}

\author{
Departments of ${ }^{1}$ Surgery and ${ }^{2}$ Clinical Laboratory, Shanghai Tongren Hospital, Shanghai 200336; \\ ${ }^{3}$ Digestive Disease Research Institute, Shanghai Huashan Hospital, Shanghai 200041, P.R. China
}

Received September 4, 2018; Accepted April 4, 2019

DOI: $10.3892 / \mathrm{mmr} .2019 .10855$

\begin{abstract}
Pancreatic cancer (PC) is the fourth leading cause of cancer-related mortality worldwide. Leptin is an adipokine that is significantly increased in obese patients and that functions in various biological processes of cancer, such as tumor growth and metastasis. However, its role in PC cell proliferation and glucose metabolism and the underlying mechanisms remain unclear. In the present study, in vitro leptin treatment significantly promoted cell proliferation and increased glucose uptake and lactate production of human PC and healthy pancreas cells in a dose-dependent manner, accompanied by increased expression of the glycolytic enzymes hexokinase II and glucose transporter 1. Furthermore, leptin receptor-specific short hairpin RNAs were used to silence leptin receptor expression in PC cells, which had the opposite effect to leptin stimulation and decreased AKT phosphorylation. In addition, the effects of leptin stimulation were significantly counteracted by the AKT inhibitor LY294002, whereas the effects of leptin silencing were counteracted by AKT activator insulin-like growth factor 1 . The results of the present study suggested that leptin may contribute to cell proliferation and glucose metabolism of human PC cells, which may be through activation of the AKT pathway.
\end{abstract}

\section{Introduction}

As the fourth leading cause of cancer mortality, pancreatic cancer (PC) is an aggressive disease, and its global prevalence has been increasing $(1,2)$. The 5 -year overall survival rate of

Correspondence to: Dr Weihong $\mathrm{Xu}$ or Dr Huiming Sheng, Department of Clinical Laboratory, Shanghai Tongren Hospital, 1111 Xianxia Road, Changning, Shanghai 200336, P.R. China

E-mail: xwh3066@126.com

E-mail:shm2783@shtrhospital.com

*Contributed equally

Key words: pancreatic cancer, leptin receptor, proliferation, glucose metabolism, AKT pathway patients diagnosed with $\mathrm{PC}$ is $<5 \%$ (3). It has been reported that obesity is one of the risk factors for PC development, and over the past decade, the rate of obesity has risen at an unprecedented rate $(4,5)$. Chronic obesity changes the production and secretion of adipokines, a type of cytokine secreted by the adipose tissue (6-9).

The adipokine leptin has been reported to be highly expressed in obese patients $(6,7)$. Leptin regulates a variety of biological processes, such as satiety, food intake and energy expenditure, through leptin receptor (LepR) (10-12). Glucose metabolism, controlled by cellular ATP and metabolite levels, offers energy and required substance for tissue anabolism and catabolism, and is essential for the growth and development of cells and tissues $(13,14)$. In addition, increasing evidence showed that glucose is an important regulator for leptin expression and secretion (15-17). LepR is composed of several isoforms including the short isoform (LepR-short) and long isoform (LepR-long). It has been reported that LepR can trigger the activation of several pathways, including PI3K/AKT and Janus-activated kinase/STAT (18-20). LepR common variant (LepR-common) is reported to influence gestation glycemic traits (21). Leptin is highly expressed in subsets of cancer patients including breast, colon and prostate cancer, and stimulates various biological activities in cancer cells, including cell proliferation, migration and invasion (22-25). Leptin is a growth factor for colon epithelial cells, and it has been demonstrated to promote motility and invasiveness in human colon cancer cells $(22,23)$. Leptin also promotes invasion and migration of breast cancer cells through transactivation of epidermal growth factor receptor (23). Pancreatic $\beta$-cells have been demonstrated to express functional LepRs, and LepR-short and LepR-long in PC cells $(4,26)$. A previous study reported that leptin signaling enhances human PC cell invasion and metastasis by increasing matrix metalloproteinase-13 (MMP-13) (27). However, the effects of LepR on the proliferation and glucose metabolism of human PC, as well as its underlying mechanisms remain unclear.

In the present study, in vitro leptin stimulation significantly promoted cell proliferation and enhanced glucose metabolism of human PC and normal pancreas cells in a dose-dependent manner, accompanied by an increase in the expression levels of the glycolytic enzymes hexokinase II (HKII) and glucose transporter 1 (GLUT1). Silencing of LepR decreased AKT 
phosphorylation. Additionally, the induction of leptin stimulation was significantly counteracted by treatment with an AKT inhibitor (LY294002), whereas the effect of LepR silencing was counteracted by the AKT activator insulin-like growth factor 1 (IGF-1). The results of the present study suggested that leptin may contribute to human PC cell proliferation and glucose metabolism, which may be through activation of the AKT pathway.

\section{Materials and methods}

Cell culture. Two human PC cell lines, BxPC3 and Panc-1, and normal pancreas cells HPC-Y5 were purchased from The Cell Bank of Type Culture Collection of the Chinese Academy of Sciences. The cells were cultured in a $37^{\circ} \mathrm{C}, 5 \%$ $\mathrm{CO}_{2}$ incubator (Thermo Forma 3111; Thermo Fisher Scientific, Inc.) in RPMI-1640 medium (cat. no. SH30809.01B; HyClone; GE Healthcare Life Sciences), which contained 10\% FBS (cat. no. 16000-044; Gibco; Thermo Fisher Scientific, Inc.) and $1 \%$ penicillin/streptomycin (cat. no. P1400-100; Beijing Solarbio Science \& Technology Co., Ltd.). The medium was refreshed every two days during incubation.

Lentiviral transduction. Short hairpin RNA (shRNA)-1 and shRNA-2 targeting two different sites of LepR (GenBank no. BC131779.1; Table I) were constructed and inserted into the Agel I/Ecol I restriction sites of a pLKO.1-puro vector (Addgene, Inc.). Following confirmation by DNA sequencing (Shanghai Majorbio Pharmaceutical Technology Co., Ltd.), LepR-shRNA-1 or LepR-shRNA-2 was co-transfected with the viral packaging plasmids psPAX2 and pMD2G (Addgene, Inc.) into 293T (The Cell Bank of Type Culture Collection of the Chinese Academy of Sciences) cells using Lipofectamine ${ }^{\circledR}$ 2000 (Invitrogen; Thermo Fisher Scientific, Inc.) in a $37^{\circ} \mathrm{C}$ incubator. The virus particles were collected by ultracentrifugation $48 \mathrm{~h}$ post-transfection.

BxPC3 cells were transduced with lentiviruses expressing shRNA negative control (shNC), LepR-shRNA-1 and LepR-shRNA-2; medium-treated cells were used as the untransfected control. Following $48 \mathrm{~h}$ of transduction by lentivirus infection in a $37^{\circ} \mathrm{C}, 5 \% \mathrm{CO}_{2}$ incubator, the silencing efficiency of LepR-shRNA-1 and LepR-shRNA-2 were evaluated by reverse transcription-quantitative PCR (RT-qPCR) and western blot analysis. Subsequently, cell proliferation, glucose uptake and lactate production, as well as the expression of several related genes and proteins including LepR-short, LepR-long, HKII, GLUT1, AKT and p-AKT, were measured at $48 \mathrm{~h}$ of transduction.

Experimental groups. BxPC3, Panc1 or HPC-Y5 cells were treated with $0,20,50$ or $100 \mathrm{ng} / \mathrm{ml}$ Leptin. Subsequently, cell proliferation, glucose uptake, lactate production as well as the expression of HKII and GLUT1 were detected. The treatment groups for BxPC3 cells were: i) RPMI-1640 medium (control); ii) shRNA negative control (shNC); iii) LepR-shRNA-1 (shRNA-1); iv) LepR-shRNA-2 (shRNA-2), or i) Medium + DMSO (control); ii) $50 \mathrm{ng} / \mathrm{ml}$ leptin + DMSO; iii) medium + $25 \mu \mathrm{mol} / 1 \mathrm{LY} 294002$ (AKT inhibitor); and iv) $50 \mathrm{ng} / \mathrm{ml}$ leptin $+25 \mu \mathrm{mol} / 1 \mathrm{LY} 294002$. A subset of shNC and shRNA-2-transfected BxPC3 cells were further treated with DMSO or
$50 \mathrm{ng} / \mathrm{ml}$ IGF-1 (AKT activator). Following treatment, cell proliferation, glucose uptake, lactate production, and the expression of several related genes (HKII, GLUT1, AKT and p-AKT) were examined.

Proliferation assay. The proliferation of treated human $\mathrm{PC}$ cells (BxPC3 and Panc1) and normal pancreas cells HPC-Y5 were evaluated by the Cell Counting Kit-8 assay (CCK-8; cat. no. CP002; SAB Biotherapeutics, Inc.). Human PC cells were seeded in 96 -well plates $\left(3 \times 10^{3}\right.$ cells/well) and cultured in a $37^{\circ} \mathrm{C}, 5 \% \mathrm{CO}_{2}$ incubator overnight. Following treatment for $24 \mathrm{~h}, 100 \mu \mathrm{l} \mathrm{CCK}-8$ solution (diluted 1:10 in serum-free medium) was added and incubated for $1 \mathrm{~h}$ in a $37^{\circ} \mathrm{C}, 5 \% \mathrm{CO}_{2}$ incubator. Subsequently, the absorbance value [optical density (OD)] at $450 \mathrm{~nm}$ was determined using a microplate reader (DNM-9602; Perlong Medical Equipment Co., Ltd.).

Detection of glucose uptake and lactate production. Human PC cells (BxPC3 and Panc1) and normal pancreas cell HPC-Y5 in the logarithmic growth phase were inoculated in 6 -well plates $\left(5 \times 10^{5}\right.$ cells/well) and cultured in a $37^{\circ} \mathrm{C}$ incubator overnight. After treatment with a range of leptin concentrations $(0,20,50$ and $100 \mathrm{ng} / \mathrm{ml})$ or according to the grouping aforementioned, the cells were cultured for $3 \mathrm{~h}$ in low-glucose DMEM, followed by washing with glucose-free Krebs-Ringer bicarbonate buffer (containing 2\% BSA) at $37^{\circ} \mathrm{C}$. The cells were subsequently incubated in glucose-free DMEM containing $100 \mu \mathrm{M}$ 2-NBDG (cat. no. 0467597-16; Cayman Chemical Company) for $45 \mathrm{~min}$, and glucose uptake was evaluated using a 2-NBDG Glucose Uptake Assay kit (Nanjing Jiancheng Bioengineering Institute). Lactate production was evaluated using a Lactate Assay Kit (Nanjing Jiancheng Bioengineering Institute). The supernatant of the treated cells was prepared according to the manufacturer's protocol and the OD was measured at $530 \mathrm{~nm}$ using a spectrophotometer.

$R T-q P C R$. Following treatment, total RNA from human PC cells (BxPC3 and Panc1) and normal pancreas cells HPC-Y5 was extracted using TRIzol reagent (cat. no. 1596-026; Invitrogen; Thermo Fisher Scientific, Inc.). Following RNA quantification and confirmation of RNA integrity by electrophoresis with $1 \%$ gel, $1 \mu \mathrm{g}$ of RNA was reverse transcribed into cDNA using the RevertAid First strand cDNA synthesis kit (cat. no. K1622; Fermentas; Thermo Fisher Scientific, Inc.). RT-qPCR was performed in triplicate using an ABI-7300 Real-Time PCR System (Applied Biosystems, Thermo Fisher Scientific, Inc., USA) and the Maxima SYBR Green/ROX qPCR Master Mix kit (cat. no. K0223; Thermo Fisher Scientific, Inc.). GAPDH was used as an internal reference. mRNA expression levels of HKII, GLUT1, LepR-common, LepR-short and LepR-long were analyzed using the $2^{-\Delta \Delta \mathrm{CT}}$ method (28). The primers used were as follows: HKII, forward 5'-ACGACA GCATCATTGTTAAGG-3', reverse 5'-TTTGGCAAAGTG AGGATGTAG-3'; GLUT1, forward 5'-TGCAGGAGATGA AGGAAG-3', reverse 5'-CAATGGTGGCATACACAG-3'; LepR-common, forward 5'-TTGTGCCAGTAATTATTT CCTCTT-3', reverse 5'-CACACCAAAGAATGAAAAAGC TAT-3'; LepR-short, forward 5'-TTCCTGGGCACAAGG 
Table I. Leptin receptor interference target design results.

Name

Sequence

Leptin receptor target site $1(842-860)$

Sense 5'-GGGUACUGAGGUAACCUAUUU-3'

Antisense 5'-AUAGGUUACCUCAGUACCCUU-3'

Leptin receptor target site 2 (863-881)

Sense 5'-GGACGAAAGCCAGAGACAAUU-3'

Antisense 5'-UUGUCUCUGGCUUUCGUCCUU-3'

ACTTA-3'- reverse 5'-GCTCCAAAAGAAGAGGACCA-3'; LepR-long, forward 5'-TTCCTGGGCACAAGGACTTA-3', reverse 5'-TTTGTGTCCCTGGGTACTTGA-3'; GAPDH, forward 5'-AATCCCATCACCATCTTC-3', reverse 5'-AGG CTGTTGTCATACTTC-3'. The thermocycling conditions were as follows: $95^{\circ} \mathrm{C}$ for $10 \mathrm{~min}$; followed by 40 cycles of $95^{\circ} \mathrm{C}$ for $15 \mathrm{sec}$ and $60^{\circ} \mathrm{C}$ for $45 \sec (29)$.

Western blot analysis. Following the various treatments, total protein from human PC cells (BxPC3 and Panc1) and normal pancreas cells HPC-Y5 were extracted using RIPA buffer supplemented with protease and phosphatase inhibitors (cat. no. R0010; Beijing Solarbio Science \& Technology Co., Ltd.), followed by quantification by the BCA Kit (cat. no. PICPI23223; Thermo Fisher Scientific, Inc.). Proteins $(25 \mu \mathrm{g})$ were separated using 10 (spacer) and $8 \%$ (separation) SDS-PAGE, and transferred to PVDF membranes (cat. no. HATF00010; EMD Millipore). Subsequently, the membranes were blocked in 5\% skimmed milk (cat. no. BYL40422; BD Biosciences) for $1 \mathrm{~h}$ at room temperature and incubated with primary antibodies against GLUT1 (1:1,000; cat. no. ab115730; Abcam), HKII [1:1,000; cat. no. 2867; Cell Signaling Technology (CST)], AKT (1:1,000; cat. no. 2920; CST), phosphorylated (p)-AKT (1:2,000; cat. no. 4060; CST), LepR-long (1:250; cat. no. sc-1835; Santa Cruz Biotechnology, Inc., California, USA), LepR-short (1:250; catalog no. sc-8325; Santa Cruz Biotechnology, Inc.) and GAPDH (1:1,000; cat. no. 5174; CST) overnight at $4^{\circ} \mathrm{C}$ with gentle agitation. Following 5-6 washes in TBS $+0.1 \%$ Tween-20, the membranes were incubated for $2 \mathrm{~h}$ at room temperature with horseradish peroxidase-conjugated goat anti-rabbit secondary antibody (1:1,000; cat. no. ZB2301, OriGene Technologies, Inc.). The blots were visualized by ECL reagent (cat. no. WBKLS0100; EMD Millipore) and images were captured with a Tanon-5200 ECL imaging system (Tanon Science and Technology Co., Ltd.). Protein expressions levels were normalized to GAPDH and analyzed using ImageJ $1.47 \mathrm{v}$ (National Institutes of Health).

Statistical analysis. All statistical analyses and calculations in this study were carried out using GraphPad Prism 7.0 software (GraphPad Software, Inc.). The statistical significance of differences between the two groups was determined using two-tailed Student's t-test, and multiple comparisons were made by one-way ANOVA followed by Tukey's test for multiple comparisons. All experiments were performed in triplicate, and data are expressed as the mean \pm standard deviation. $\mathrm{P}<0.05$ was considered to indicate a statistically significant difference.

\section{Results}

Leptin stimulates the proliferation and glucose metabolism of human PC cells. Human PC cell lines, BxPC3 and Panc1, and normal pancreas cells were treated with increasing concentrations of leptin $(0,20,50$ and $100 \mathrm{ng} / \mathrm{ml})$ for $24 \mathrm{~h}$. In vitro treatment with leptin significantly stimulated the proliferation of BxPC3 and Panc1 cells as well as pancreas cells HPC-Y5 in a dose-dependent manner (Fig. 1A). These results indicated that leptin stimulation may promote the proliferation of human PC and pancreas cells. In addition, glucose uptake (Fig. 1B) and lactate production (Fig. 1C) of BxPC3, Panc1 and pancreas cells were markedly increased by leptin stimulation, accompanied by increased expression of HKII and GLUT1 (Fig. 1D and E). These data suggested that leptin stimulation may contribute to glucose metabolism and proliferation of human PC cells and healthy pancreatic cells.

Silencing of LepR expression levels in BxPC3 cells. Due to the significant increase of proliferation, glucose uptake and lactate production in both $\mathrm{BxPC} 3$ and Panc1 cells, in the present study, one cell line, BxPC3, was selected for further investigation. BxPC3 cells were infected with lentiviruses expressing shNC, LepR-shRNA-1 and LepR-shRNA-2; untreated cells were used as a control. mRNA expression of LepR-common, LepR-short and LepR-long (Fig. 2A), as well as the protein expression levels of LepR-short and LepR-long, were significantly downregulated by LepR-shRNA-1 and LepR-shRNA-2 (Fig. 2B). Therefore, the LepR-shRNA-1 and LepR-shRNA-2 vectors were used for subsequent experiments.

Silencing of LepR inhibits proliferation and glucose metabolism of human PC cells. To investigate the role of leptin in human PC cells, proliferation, glucose uptake and lactate production were assessed in BxPC3 cells following LepR silencing. The results indicated that the proliferation of $\mathrm{BxPC} 3$ cells was notably suppressed by silencing of LepR, compared with the control groups (Fig. 3A). Glucose uptake (Fig. 3B) and lactate production (Fig. 3C) of BxPC3 cells were also inhibited, accompanied by decreased protein expression levels of HKII, GLUT1 and p-AKT, whereas total AKT protein expression was unaltered (Fig. 3D), suggesting an inhibitory effect of leptin silencing on AKT activation. These results demonstrated the beneficial effects of leptin in glucose metabolism 
A
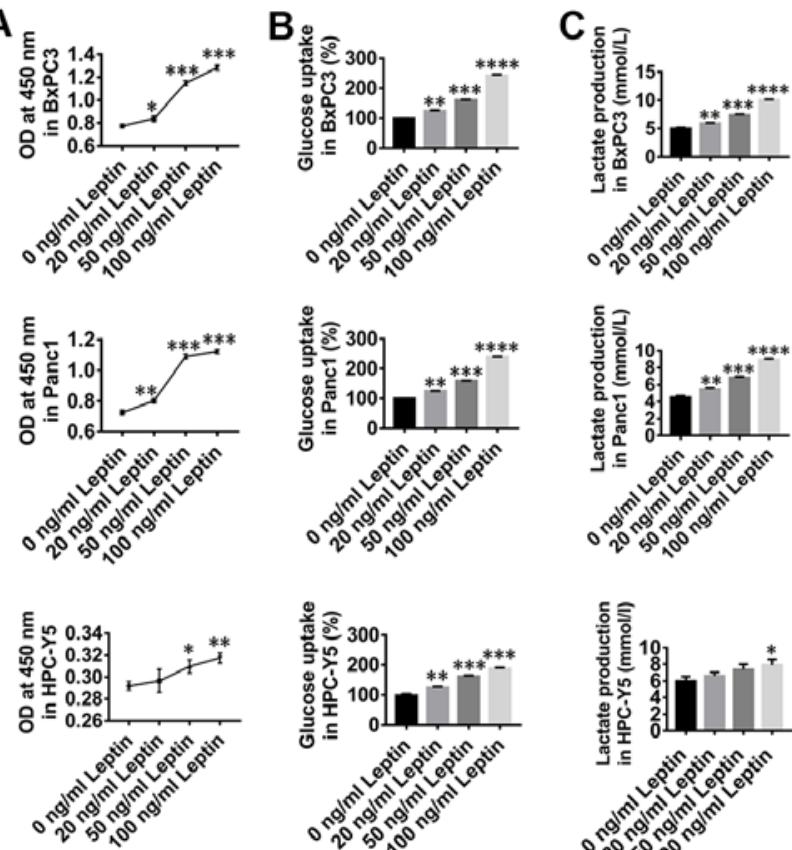
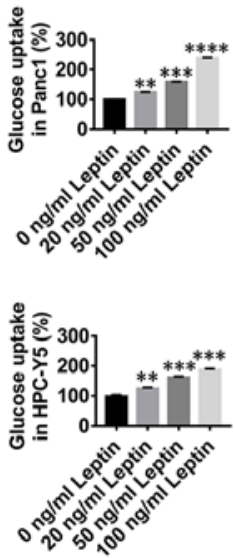

D
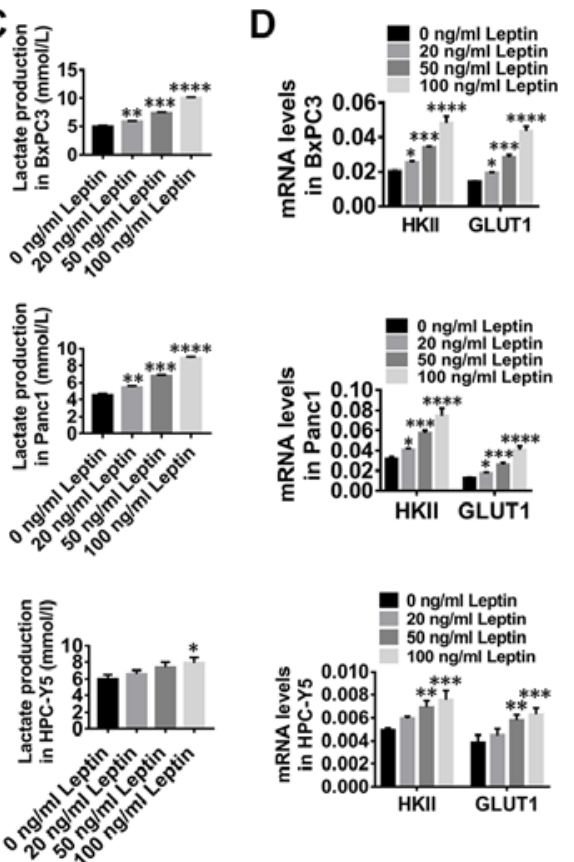

E
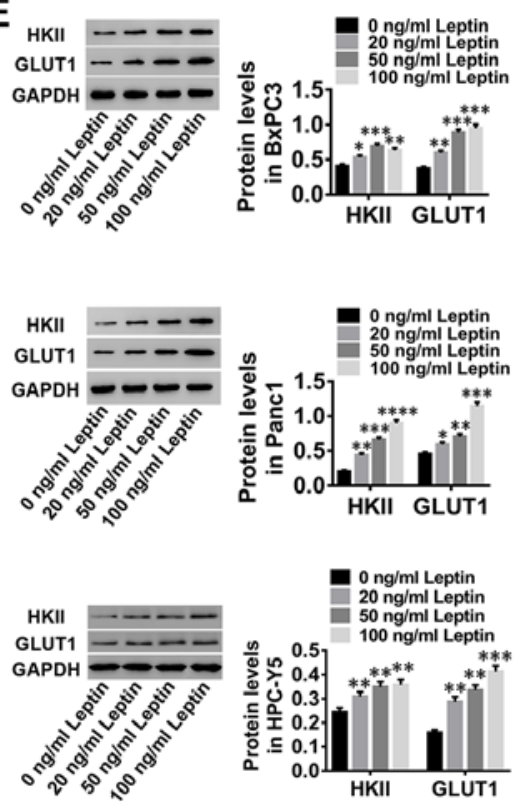

Figure 1. Leptin stimulates the proliferation and glucose metabolism of human PC and normal pancreas cells. (A) The proliferation of BxPC3 (top), Panc1 (middle) and normal pancreas cells HPC-Y5 (bottom) was assessed by Cell Counting Kit-8. (B) Glucose uptake and (C) lactate production were respectively detected by a 2-NBDG kit and a Lactate Assay Kit, respectively. (D) mRNA and (E) protein levels of GLUT1 and HKII were determined by reverse transcription-quantitative PCR and western blotting, respectively. ${ }^{*} \mathrm{P}<0.05 ;{ }^{* *} \mathrm{P}<0.01 ;{ }^{* * *} \mathrm{P}<0.001 ;{ }^{* * * * *} \mathrm{P}<0.0001 \mathrm{vs} .0 \mathrm{ng} / \mathrm{ml}$ leptin. GLUT1, glucose transporter 1 ; HKII, hexokinase II; OD, optical density.
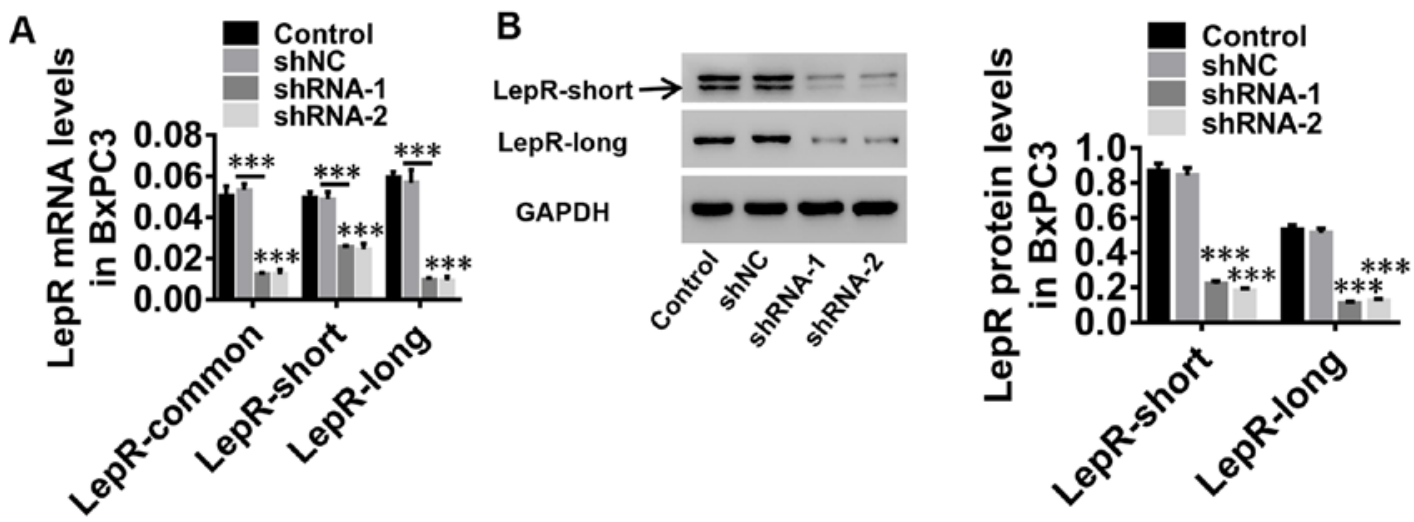

Figure 2. Silencing of LepR expression levels in BxPC3 cells. (A and B) BxPC cells were infected with lentiviruses expressing shNC, LepR-shRNA-1 and shRNA-2; untreated cells were used as control. (A) mRNA expression of LepR-common, LepR-short and LepR-long was detected by reverse transcription-quantitative PCR. (B) Protein levels of LepR-short and LepR-long were detected by western blot analysis. ${ }^{* * *} \mathrm{P}<0.001$ vs. shNC. LepR, leptin receptor; shNC, negative control shRNA; shRNA, short hairpin RNA.

and proliferation of human PC cells, which may be involved in AKT pathway activation.

Leptin stimulates the proliferation and glucose metabolism of human PC cells via activation of the AKT pathway. The molecular mechanisms of leptin in mediating glucose metabolism and proliferation of human PC cells were explored. Leptin-stimulated proliferation, glucose uptake and lactate production were effectively counteracted by co-treatment with the AKT inhibitor LY294002 (Fig. 4A-C, respectively). The increased protein expression levels of HKII, GLUT1 and p-AKT induced by leptin stimulation were also significantly decreased (Fig. 4D), whereas total AKT was unchanged
(Fig. 4D). Leptin stimulation potently attenuated the effects of AKT inhibitor, LY294002, suggesting that there was a rescue effect of leptin stimulation on AKT inhibition. In addition, the inhibition of proliferation, glucose uptake and lactate production induced by Lep2-shRNA-2 transfection were significantly counteracted by co-treatment with the AKT activator IGF-1 (Fig. 4E-G, respectively), accompanied by an increased expression of GLUT1 and HKII protein (Fig. 4H). In the present study, Lep2-shRNA-2 was used due to its better downregulation efficiency compared with shRNA-1. These results further demonstrated that leptin may stimulate glucose metabolism and proliferation of human PC cells potentially through activating the AKT pathway. 

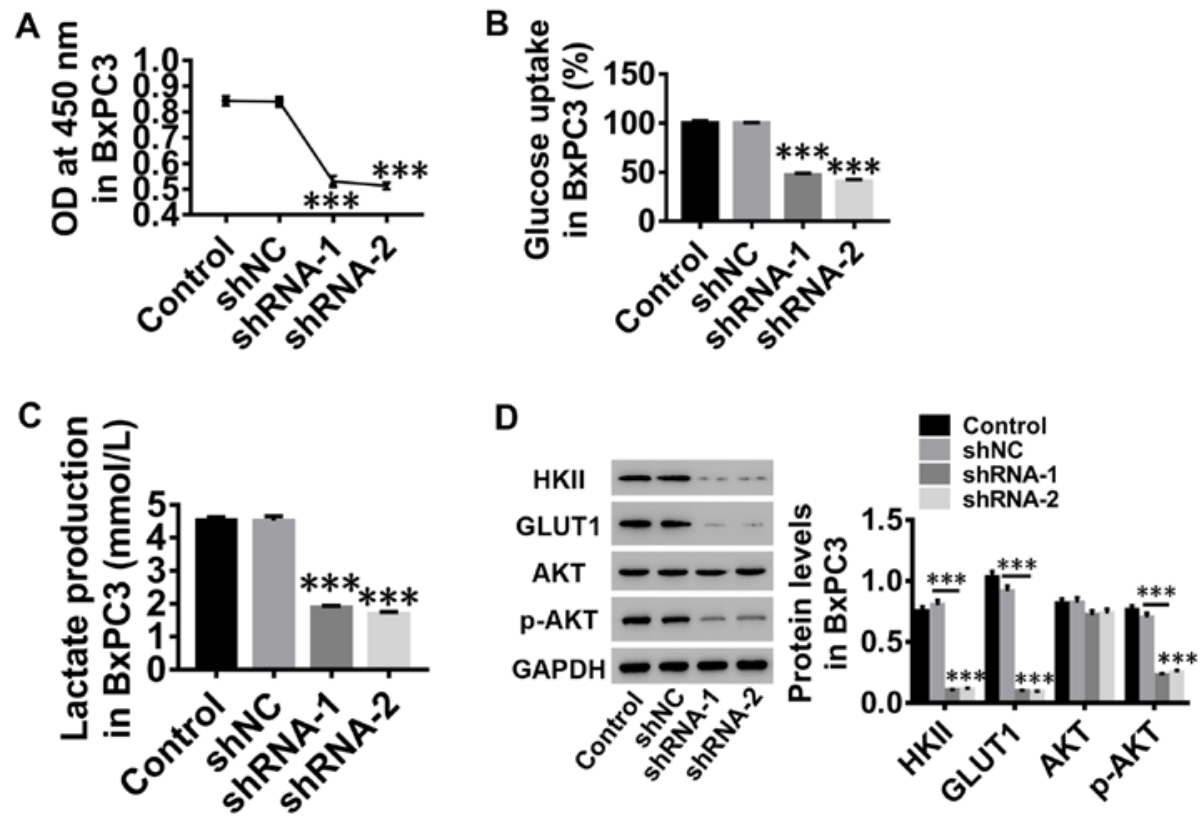

Figure 3. Silencing of LepR reduces the proliferation and glucose metabolism of human PC cells. (A-C) BxPC3 cells were transduced with LepR-shRNA-1 and LepR-shRNA-2. (A) Cell proliferation was assessed by the Cell Counting Kit-8 assay, which demonstrated that LepR silencing reduced cell proliferation. (B and C) Glucose uptake and lactate production were also decreased by the shRNAs. (D) Reduced expression levels of GLUT1, HKII, p-AKT and AKT proteins were detected following lentiviral infection with shRNA. ${ }^{* * *} \mathrm{P}<0.001$ vs. shNC. GLUT1, glucose transporter 1; HKII, hexokinase II; p-AKT, phosphorylated AKT; shNC, negative control shRNA; shRNA, short hairpin RNA.

A

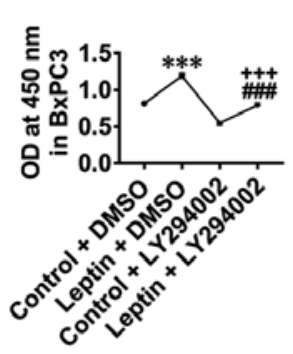

E

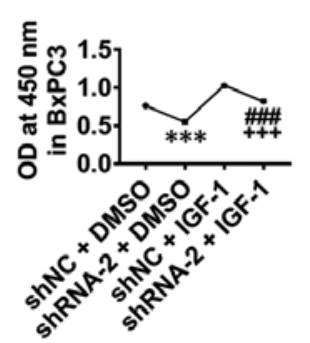

B

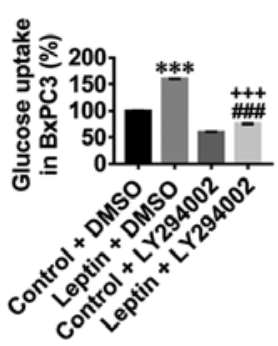

F

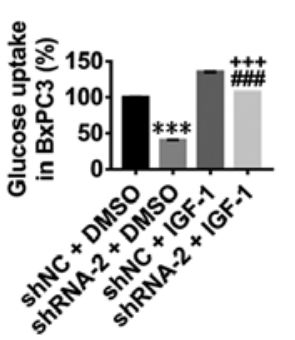

C

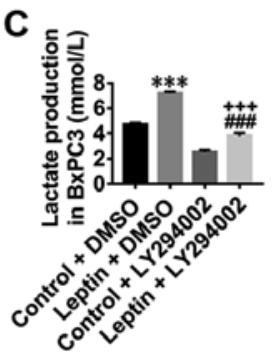

G

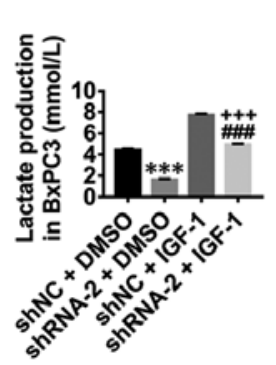

D
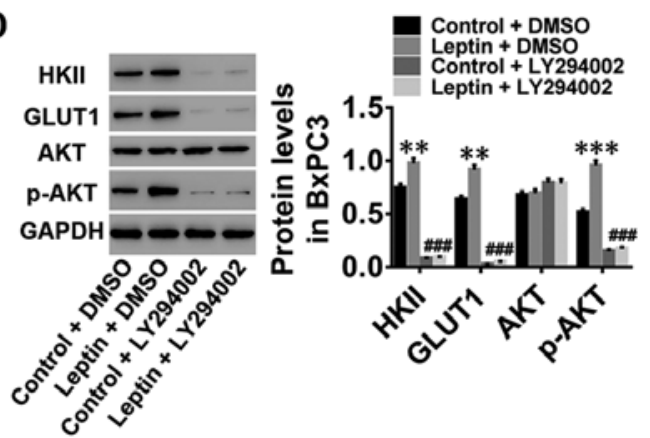

H

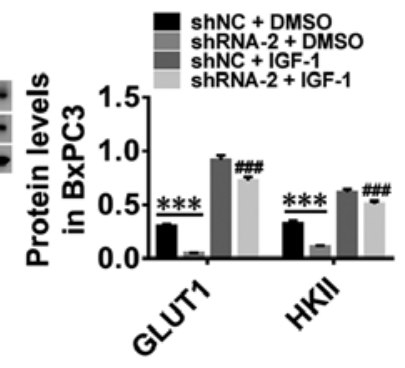

Figure 4. Leptin stimulates the proliferation and glucose metabolism of human PC cells via activation of the AKT pathway. BxPC3 cells were treated with medium (control), $50 \mathrm{ng} / \mathrm{ml}$ leptin, medium $+25 \mu \mathrm{mol} / 1 \mathrm{LY} 294002$ (an AKT inhibitor), or $50 \mathrm{ng} / \mathrm{ml}$ leptin $+25 \mu \mathrm{mol} / 1 \mathrm{LY} 294002$. (A) Cell proliferation was assessed. (B) Glucose uptake was calculated. (C) Lactate production was calculated. (D) The protein levels of GLUT1, HKII and the p-AKT/total AKT ratio were detected. BxPC3 cells were treated with shNC, shRNA-2, shNC $+50 \mathrm{ng} / \mathrm{ml}$ IGF-1 (an AKT activator), and shRNA-2 + 50 ng/ml IGF-1. (E) Cell proliferation was assessed. (F) Glucose uptake was calculated. (G) Lactate production was calculated. (H) The protein levels of GLUT1, HKII were detected. ${ }^{* * *} \mathrm{P}<0.01$ and ${ }^{* * *} \mathrm{P}<0.001$ vs. control + DMSO or shNC + DMSO; ${ }^{\# \#} \mathrm{P}<0.001$ vs. leptin + DMSO or shRNA-2 + DMSO; ${ }^{+++} \mathrm{P}<0.001$ vs. control + LY294002 or shNC + IGF-1. GLUT1, glucose transporter 1; HKII, hexokinase II; p-AKT, phosphorylated AKT; shNC, negative control shRNA; shRNA, short hairpin RNA.

\section{Discussion}

Leptin is a hormone that is highly expressed in overweight and obese individuals and may be involved in the progression of many cancers. Previous studies have shown that leptin can stimulate the proliferation of various cancer cell lines (30-33). An increase in leptin was reported in plasma and pancreatic tissue, suggesting that leptin may be involved in tumor growth 
in the pancreas (4). The distribution and high abundance of positive leptin or LepR in tumor tissue samples of PC patients have been described in our previous study (27). Leptin acts as a growth factor to promote proliferation in multiple cancers, such as breast and lung cancer $(34,35)$. Leptin stimulates cell proliferation and survival in breast cancer cells through LepR $(36,37)$. In the current study, leptin stimulation promoted the glucose metabolism and proliferation of human PC cells and non-cancerous cells. Silencing of LepR by LepR-shRNAs had the opposite effect as leptin stimulation on human PC cells, which agreed with a previous report (38) and suggested that LepR knockdown may attenuate human PC progression by mediating glucose metabolism and cell proliferation.

The underlying mechanisms of LepR on human PC cell growth were also explored. GLUT1 and HKII are two key enzymes that regulate cellular glycolysis and energy metabolism. HKII has been demonstrated to be the key enzyme to catalyze the first step in the glycolytic pathway $(39,40)$, and GLUT1 typically regulates the first rate-limiting step of glucose metabolism when glucose flows into cells $(41,42)$. The results of the present study demonstrated that GLUT1 and HKII expression in human PC cells and healthy pancreatic cells was significantly increased by leptin stimulation, but LepR silencing in human PC cells significantly decreased GLUT1 and HKII expression. Studies have showed that leptin is a cytokine with multiple biological roles including regulation of energy metabolism and plays an important role in cell proliferation, invasion, metastasis and survival in cancers including breast, esophageal and endometrial cancers (43-46). Thus, the increase of GLUT1 and HKII expression in healthy pancreas cells may be caused by the stimulation of leptin. In our previous study, compared with normal tissues, high abundance of positive leptin or LepR was found in tumor tissue samples of PC patients (27). These results demonstrated that leptin may be a molecular switch that regulates glycolytic-related proteins such as GLUT1 and HKII, thus regulating glucose metabolism of human PC cells. The PI3K/AKT pathway has been suggested to be the main signaling cascade in glucose metabolism and cell growth regulation. It is known that activation of AKT regulates cell growth and controls the rates of glucose uptake through the GLUT1 transporter. It has also been found that AKT can further affect glycolysis through HKII (47-50). Therefore, the AKT pathway was analyzed in the present study. GLUT1, HKII and p-AKT were significantly decreased by the silencing of leptin receptor, whereas AKT levels were unchanged. Additionally, high levels of GLUT1, HKII and p-AKT induced by leptin stimulation were effectively counteracted by co-treatment with the AKT inhibitor LY294002, whereas inhibition of GLUT1, HKII and p-AKT by LepR silencing was counteracted by IGF-1 co-treatment. Increased levels of GLUT1 have been reported to enhance glucose uptake, which in turn elevates the rate of glycolysis to enhance ATP production, ultimately enhancing the growth of tumors (51). These findings demonstrated that LepR may contribute to the glucose metabolism and proliferation of human PC cells in vitro, possibly through the activation of the AKT pathway. Compared with our previous studies and other related studies $(27,52-54)$ which reported that leptin enhances $\mathrm{PC}$ invasion through the increase in MMP-13 production but does not affect PC cell proliferation, the present study targeted LepR instead of leptin and revealed that LepR had an effect on the proliferation and metabolism of PC cells and further demonstrated that this regulation may be through the activation of the AKT signaling pathway. Therefore, targeting the LepR/AKT signaling pathway is a potential therapeutic strategy for PC. However, the current results are based solely on in vitro experiments and are therefore not comprehensive enough. Further in vivo studies should be conducted in the future to confirm these results.

In conclusion, the present study demonstrated that knockdown of LepR may attenuate the development of human PC by inhibiting glucose metabolism and cell proliferation. LepR has the potential to be a molecular switch that regulates glycolysis-related proteins such as GLUT1 and HKII through activation of the AKT pathway, further regulating glucose metabolism and proliferation in human PC cells. These findings offer the foundation for further study of the role of LepR in the relief or treatment of pancreatic cancer.

\section{Acknowledgements}

Not applicable.

\section{Funding}

This work was funded by The National Natural Science Foundation of China (grant no. 81672083), Shanghai No. 6 People's Hospital group project (grant no. 2016jy201602) and Shanghai Jiao Tong University Medical and Engineering Cross Subject (grant no. YG2016MS69).

\section{Availability of data and materials}

All data generated or analyzed during this study are included in this published article.

\section{Authors' contributions}

WX and HS conceived and designed the study. YX, MT, XT, JuZ, JiZ and JC performed the experiments. WX and HS wrote the manuscript. All authors read and approved the final manuscript.

\section{Ethics approval and consent to participate}

Not applicable.

\section{Patient consent for publication}

Not applicable.

\section{Competing interests}

The authors declare that they have no competing interests.

\section{References}

1. Hidalgo M: Pancreatic cancer. N Engl J Med 362: 1605-1617, 2010.

2. Vincent A, Herman J, Schulick R, Hruban RH and Goggins M: Pancreatic cancer. Lancet 378: 607-620, 2011. 
3. Harbuzariu A, Daley-Brown DS, Harmon TL, Garrison RC, Beech DJ, Cason FD, Klug C and Gonzalez-Perez RR: Abstract B26: Leptin affects proliferation, stem cells and chemotherapeutic treatment outcome of pancreatic cancer: A link to health disparity. Cancer Epidemiol Biomarkers Prev 25: B26, 2016.

4. Mendonsa AM, Chalfant MC, Gorden LD and VanSaun MN: Modulation of the leptin receptor mediates tumor growth and migration of pancreatic cancer cells. PLoS One 10: e0126686, 2015

5. Ng M, Fleming T, Robinson M, Thomson B, Graetz N, Margono C, Mullany EC, Biryukov S, Abbafati C, Abera SF, et al: Global, regional, and national prevalence of overweight and obesity in children and adults 1980-2013: A systematic analysis for the Global Burden of Disease Study 2013. Lancet 384: 766-781, 2014.

6. Inadera $\mathrm{H}$ : The usefulness of circulating adipokine levels for the assessment of obesity-related health problems. Int J Med Sci 5: 248-262, 2008

7. de Luis DA, González Sagrado M, Conde R, Aller R, Izaola O and Castro MJ: Circulating adipocytokines in morbid obese patients, relation with cardiovascular risk factors and anthropometric parameters. Nutr Hosp 26: 91-96, 2011.

8. Ebert T, Roth I, Richter J, Tönjes A, Kralisch S, Lossner U, Kratzsch J, Blüher M, Stumvoll M and Fasshauer M: Different associations of adipokines in lean and healthy adults. Horm Metab Res 46: 41-47, 2014.

9. Balistreri CR, Caruso C and Candore G: The role of adipose tissue and adipokines in obesity-related inflammatory diseases. Mediators Inflamm 2010: 802078, 2010.

10. Collins S, Kuhn CM, Petro AE, Swick AG, Chrunyk BA and Surwit RS: Role of leptin in fat regulation. Nature 380: 677, 1996.

11. Lindheim SR, Sauer MV, Carmina E, Chang PL, Zimmerman R and Lobo RA: Circulating leptin levels during ovulation induction: Relation to adiposity and ovarian morphology. Fertil Steril 73: 493-498, 2000

12. Henson $\mathbf{M}$ and Castracane V: Leptin in pregnancy. Biol Reprod 63: 1219-1228, 2000.

13. Shaw RJ: Glucose metabolism and cancer. Curr Opin Cell Biol 18: 598-608, 2006

14. Jiang $\mathrm{G}$ and Zhang BB: Glucagon and regulation of glucose metabolism. Am J Physiol Endocrinol Metab 284: E671-E678, 2003.

15. Mueller WM, Gregoire FM, Stanhope KL, Mobbs CV, Mizuno TM, Warden CH, Stern JS and Havel PJ: Evidence that glucose metabolism regulates leptin secretion from cultured rat adipocytes. Endocrinology 139: 551-558, 1998.

16. Frühbeck $G$ and Salvador J: Relation between leptin and the regulation of glucose metabolism. Diabetologia 43: 3-12, 2000.

17. Morton GJ and Schwartz MW: Leptin and the central nervous system control of glucose metabolism. Physiol Rev 91: 389-411, 2011.

18. Ceddia RB: Direct metabolic regulation in skeletal muscle and fat tissue by leptin: Implications for glucose and fatty acids homeostasis. Int J Obes (Lond) 29: 1175-1183, 2005.

19. Vansaun MN: Molecular pathways: Adiponectin and leptin signaling in cancer. Clin Cancer Res 19: 1926-1932, 2013.

20. Cottrell EC and Mercer JG: Leptin receptors. Handb Exp Pharmacol 209: 3-21, 2012.

21. Lin R, Ju H, Yuan Z, Zeng L, Sun Y, Su Z, Yang Y, Wang Y and Jin L: Association of maternal and fetal LEPR common variants with maternal glycemic traits during pregnancy. Sci Rep 7: 3112, 2017.

22. Hardwick JC, Van Den Brink GR, Offerhaus GJ, Van Deventer SJ and Peppelenbosch MP: Leptin is a growth factor for colonic epithelial cells. Gastroenterology 121: 79-90, 2001.

23. Jaffe T and Schwartz B: Leptin promotes motility and invasiveness in human colon cancer cells by activating multiple signal-transduction pathways. Int J Cancer 123: 2543-2556, 2008

24. Saxena NK, Taliaferro-Smith LT, Knight BB, Merlin D, Anania FA, O'Regan RM and Sharma D: Bidirectional crosstalk between leptin and insulin-like growth factor-I signaling promotes invasion and migration of breast cancer cells via transactivation of epidermal growth factor receptor. Cancer Res 68 : 9712-9722, 2008.

25. Fava G, Alpini G, Rychlicki C, Saccomanno S, DeMorrow S, Trozzi L, Candelaresi C, Venter J, Di Sario A, Marzioni M, et al: Leptin enhances cholangiocarcinoma cell growth. Cancer Res 68: 6752-6761, 2008

26. Islam MS, Morton NM, Hansson A and Emilsson V: Rat insulinoma-derived pancreatic beta-cells express a functional leptin receptor that mediates a proliferative response. Biochem Biophys Res Commun 238: 851-855, 1997.
27. Fan Y, Gan Y, Shen Y, Cai X, Song Y, Zhao F, Yao M, Gu J and $\mathrm{Tu} H$ : Leptin signaling enhances cell invasion and promotes the metastasis of human pancreatic cancer via increasing MMP-13 production. Oncotarget 6: 16120-16134, 2015.

28. Livak KJ and Schmittgen TD: Analysis of relative gene expression data using real-time quantitative PCR and the 2(-Delta Delta $\mathrm{C}(\mathrm{T})$ ) method. Methods 25: 402-408, 2001.

29. Hong JY, Kang B, Kim A, Hwang S, Ahn J, Lee S, Kim J, Park JH and Cheon DS: Development of a highly sensitive real-time one step RT-PCR combined complementary locked primer technology and conjugated minor groove binder probe. Virol J 8: 330, 2011.

30. Han G, Wang L, Zhao R, Yue Z, Zhou X, Hu X, Cao Y, Dai D and Liu J: Leptin promotes human glioblastoma growth through activating Signal Transducers and Activators of Transcription 3 signaling. Brain Res Bull 87: 274-279, 2012.

31. Liu Y, Lv L, Xiao W, Gong C, Yin J, Wang D and Sheng H: Leptin activates STAT3 and ERK1/2 pathways and induces endometrial cancer cell proliferation. J Huazhong Univ Sci Technolog Med Sci 31: 365, 2011

32. Endo H, Hosono K, Uchiyama T, Sakai E, Sugiyama M, Takahashi H, Nakajima N, Wada K, Takeda K, Nakagama H and Nakajima A: Leptin acts as a growth factor for colorectal tumours at stages subsequent to tumour initiation in murine colon carcinogenesis. Gut 60: 1363-1371, 2011

33. Saxena NK, Vertino PM, Anania FA and Sharma D: Leptin-induced growth stimulation of breast cancer cells involves recruitment of histone acetyltransferases and mediator complex to CYCLIN D1 promoter via activation of Stat3. J Biol Chem 282: 13316-13325, 2007.

34. Garofalo C and Surmacz E: Leptin and cancer. J Cell Physiol 207: 12-22, 2010.

35. Somasundar P, McFadden DW, Hileman SM and Vona-Davis L: Leptin is a growth factor in cancer. J Surg Res 116: 337-349, 2004.

36. Hu X, Juneja SC, Maihle NJ and Cleary MP: Leptin-A growth factor in normal and malignant breast cells and for normal mammary gland development. J Natl Cancer Inst 95: 1704-1711, 2002.

37. Dieudonne MN, Machinal-Quelin F, Serazin-Leroy V, Leneveu MC, Pecquery R and Giudicelli Y: Leptin mediates a proliferative response in human MCF7 breast cancer cells. Biochem Biophys Res Commun 293: 622-628, 2002.

38. Krechler T, Zeman M, Vecka M, Macasek J, Jachymova M, Zima $\mathrm{T}$ and Zak A: Leptin and adiponectin in pancreatic cancer: Connection with diabetes mellitus. Neoplasma 58 58-64, 2011

39. Lv X, Yao L, Zhang J, Han $\mathrm{P}$ and Li C: Inhibition of microRNA-155 sensitizes lung cancer cells to irradiation via suppression of HK2-modulated glucose metabolism. Mol Med Rep 14: 1332-1338, 2016.

40. Fang R, Xiao T, Fang Z, Sun Y, Li F, Gao Y, Feng Y, Li L, Wang Y, Liu X, et al: MicroRNA-143 (miR-143) regulates cancer glycolysis via targeting hexokinase 2 gene. J Biol Chem 287: 23227-23235, 2012.

41. Fan R, Hou WJ, Zhao YJ, Liu SL, Qiu XS, Wang EH and Wu GP: Overexpression of HPV16 E6/E7 mediated HIF-1 $\alpha$ upregulation of GLUT1 expression in lung cancer cells. Tumour Biol 37: 4655-4663, 2016.

42. Sasaki H, Shitara M, Yokota K, Hikosaka Y, Moriyama S, Yano $\mathrm{M}$ and Fujii Y: Overexpression of GLUT1 correlates with Kras mutations in lung carcinomas. Mol Med Rep 5: 599-602, 2012.

43. Huang L and Li C: Leptin: A multifunctional hormone. Cell Res 10: 81-92, 2000

44. Ogunwobi O, Mutungi G and Beales IL: Leptin stimulates proliferation and inhibits apoptosis in Barrett's esophageal adenocarcinoma cells by cyclooxygenase-2-dependent, prostaglandin-E2-mediated transactivation of the epidermal growth factor receptor and c-Jun NH2-terminal kinase activation. Endocrinology 147: 4505-4516, 2006.

45. Saxena NK, Sharma D, Ding X, Lin S, Marra F, Merlin D and Anania FA: Concomitant activation of the JAK/STAT, $\mathrm{PI} 3 \mathrm{~K} / \mathrm{AKT}$, and ERK signaling is involved in leptin-mediated promotion of invasion and migration of hepatocellular carcinoma cells. Cancer Res 67: 2497-2507, 2007

46. Sharma D, Saxena NK, Vertino PM and Anania FA: Leptin promotes the proliferative response and invasiveness in human endometrial cancer cells by activating multiple signal-transduction pathways. Endocr Relat Cancer 13: 629-640, 2006. 
47. JóźwiakP,Krześlak A,BryśsandLipińska A: Glucose-dependent glucose transporter 1 expression and its impact on viability of thyroid cancer cells. Oncol Rep 33: 913-920, 2015.

48. Hong SY, Yu FX, Luo Y and Hagen T: Oncogenic activation of the PI3K/Akt pathway promotes cellular glucose uptake by downregulating the expression of thioredoxin-interacting protein. Cell Signal 28: 377-383, 2016.

49. Hou X, Liu Y, Liu H, Chen X, Liu M, Che H, Guo F, Wang C, Zhang D, Wu J, et al: PERK silence inhibits glioma cell growth under low glucose stress by blockage of p-AKT and subsequent HK2's mitochondria translocation. Sci Rep 5: 9065, 2015.

50. Neary CL and Pastorino JG: Akt inhibition promotes hexokinase 2 redistribution and glucose uptake in cancer cells. J Cell Physiol 228: 1943-1948, 2013.
51. Stan SD, Singh SV and Brand RE: Chemoprevention strategies for pancreatic cancer. Nat Rev Gastroenterol Hepatol 7: 347-356, 2010.

52. Bloomston M, Zervos EE and Rosemurgy AS II: Matrix metalloproteinases and their role in pancreatic cancer: A review of preclinical studies and clinical trials. Ann Surg Oncol 9: 668-674, 2002.

53. Coussens LM, Fingleton B and Matrisian LM: Matrix metalloproteinase inhibitors and cancer-trials and tribulations. Science 295: 2387-2392, 2002.

54. Vihinen P and Kähäri VM: Matrix metalloproteinases in cancer: Prognostic markers and therapeutic targets. Int J Cancer 99: 157-166, 2002. 